\title{
Universities driving cooperation and circular change
}

\author{
Dilbar Sultanova*1, and Alina Bagaveeva 20000-0003-3563-7610] \\ ${ }^{1}$ Kazan National Research Technological University, 420015 Kazan, Russia \\ ${ }^{2}$ JSC «Tatneftekhiminvest-holding», 420061 Kazan, Russia
}

\begin{abstract}
The article explores the potential for the development of cooperative processes in Russia, including under the influence of the circular economy. The analysis of the most relevant scientific schools and approaches that reveal the circular economy model is carried out. The article revealed the actual mechanisms of cooperation between business, science and education in Russia. Based on the data of the survey of enterprises of the Kama innovative territorial-production cluster, the high potential of scientific and educational organizations for involving enterprises in the process of cooperation was determined. The topic of circular economics is proposed as a basis for cooperation between universities and enterprises.

Keywords. Circular economy, «Cradle to Cradle» model, donut economic model, quintuple helix model, cluster development, world-class scientific and educational center, program of strategic academic leadership «priority 2030», complex scientific and technical programs, standardized centrality score, linear correlation coefficient.
\end{abstract}

\section{Introduction}

At the present stage, one of the main items on the global agenda is the achievement of sustainable economic growth. An uncontrolled increase in consumption volumes and an increasing anthropogenic load on the environment every year increasingly affect the quality of life and pose a serious threat to sustainable development. A balanced and effective alignment of economic, environmental and social components and their equilibrium can be achieved in a circular economy model.

Many representatives of the scientific, business and political communities suggest that new incentives for economic growth and the implementation of sustainable development goals are to change the model of the paradigm of economic growth from linear to circular. A circular economy is an economy that has a restorative and closed nature, which implies the creation of a continuous development cycle, increasing the return on resources by optimizing their use. Despite the environmental aspect, the circular economy is primarily an economy that proves the economic benefits and benefits of closed production cycles, the use of renewable resources and the conscious use of things.

According to a 2013 McKinsey \& Company study commissioned by the Ellen MacArthur

${ }^{*}$ Corresponding author: econsultan@mail.ru 
Foundation, the transition to a circular economy model could bring the global economy up to 1 trillion dollars by 2025 , as well as stimulate the creation of 100 thousand new jobs, saving 500 million dollars on materials and preventing the creation of 100 million tons of waste [1].

According to the authors, the transformation of economic space and cooperation processes under the influence of a circular economy is of scientific interest for research. This direction is of particular interest and relevance for Russia, both in the context of meeting the requirements of the international agenda, and in the context of solving internal issues of finding a working and effective model of cooperation between government, science, business and society. In some works, the possibilities of internationalization are demonstrated in the process of integrating the sphere of educational services, the applied aspects of the design of educational services are shown [2-5].

\subsection{Scientific approach to circular economy}

The circular economy model is synthesized by several scientific schools. According to the authors, among the variety of approaches, it is most expedient to single out the philosophy «from cradle to cradle». The phrase was coined in the 1970s by Walter R. Stahel, a Swiss architect, economist and pioneer of industrial sustainability [6]. In 1982, Walter R. Stahel received the Mitchell Prize for his article The Life Factor of a Product, which described what would become circular economics. The author pointed out that reusing and extending the life of goods is a strategy to prevent industrial waste, create jobs, and improve resource efficiency. According to Stahel, circular economy should be considered as a general concept, a framework that relies on more specific approaches [6].

Subsequently, the term «from cradle to cradle» was popularized by the German chemist Michael Braungarth and the American architect William McDonagh in the book «From Cradle to Cradle. We are changing the approach to how we create things», published in 2002 [7]. The authors call for a new approach in product and material design, where waste is viewed as nutrients that are continually reused in biological and technical processes. Biological processes take place in the biosphere (natural cycles), and technical ones - in the technosphere (industrial cycles).

Products can either consist of biodegradable materials that provide food for biological processes, or from technical materials that remain in a closed loop of technological processes. For the successful functioning of processes, a prerequisite is the prevention of their mixing [7].
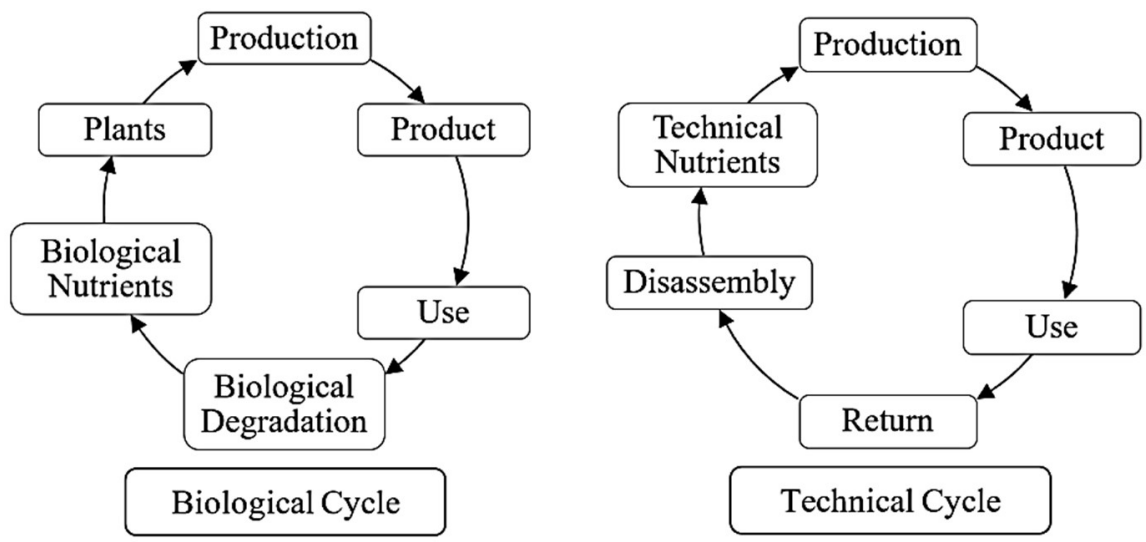

Fig. 1. Biological and technical metabolic processes in the «Cradle to Cradle» model. Source: [7]. 
One of the modern models that clearly represents the idea of sustainable development is the Donut Economic Model. The author of the model, Keith Raworth, is an English economist working for Oxford and Cambridge universities [8]. The model demonstrates the need to move away from the biased GDP indicator and strive for balanced development that also takes into account social and environmental characteristics.

Indeed, according to the authors of this article, GDP as an indicator emerged during the heyday of industrial production, when economic activity was directly associated with increased consumption, and natural resources seemed limitless. Taking into account the global agenda for achieving sustainable development, the new economic model should be based on different indicators, and the transition to a circular economy will entail a decrease in consumer activity due to more responsible consumption.

The donut forms two circles: a social base (inner border) and an ecological ceiling (outer). The inner circle is the basis that guarantees the social well-being of society (material goods, basic needs, etc.). Outer circle - environmental standards that cannot be exceeded (air and soil pollution, ozone depletion, global warming, etc.).

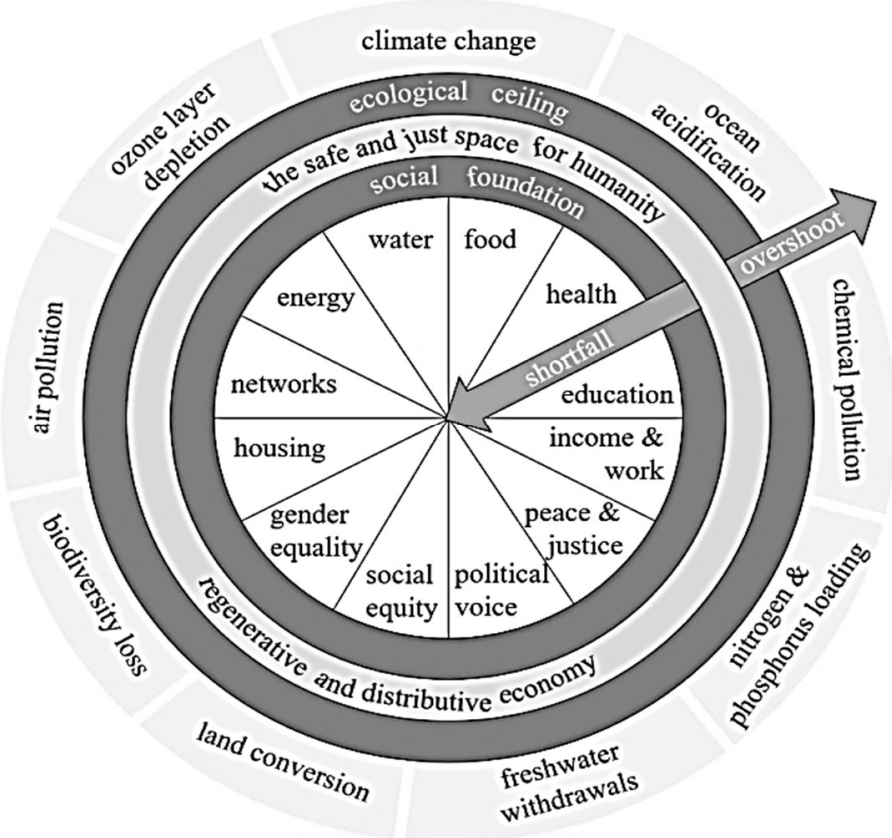

Fig. 2. Donut Economic Model Graphic. Source: [8].

Both failures to fulfill the foundations for social well-being (sinking into the donut hole) and causing damage to the environment (going beyond the outer circle) are critical. The goal of the policy according to the Donut Model is to balance the inner and outer circumference, to develop the economy to be in the «dough» of the donut.

In 2020, the City of Amsterdam adopted an urban strategy for a circular economy until 2025, which is based on the Donut Model [9]. This is the first example of the implementation of this model at the city level. It is planned to completely revise the system of production, consumption and processing: by 2030 the city will halve the consumption of new raw materials, and by 2050 it will switch to a circular economy. 
There is also the Quintuple Helix model, which distinguishes the education system, the media system and society, as well as the economic, political and natural systems. The Quintuple Helix model is presented in a joint study by E. Karayannis, T. Bart and D. Campbell [10]. This model focuses on sustainable development through the socio-ecological transition of society and economy, which acts as a driver for additional knowledge and better innovations. In other words, Quintuple Helix model is a model of the relationship between knowledge and innovation, contributing to sustainable development, where the natural environment is a central component of the production of knowledge and innovation [10].

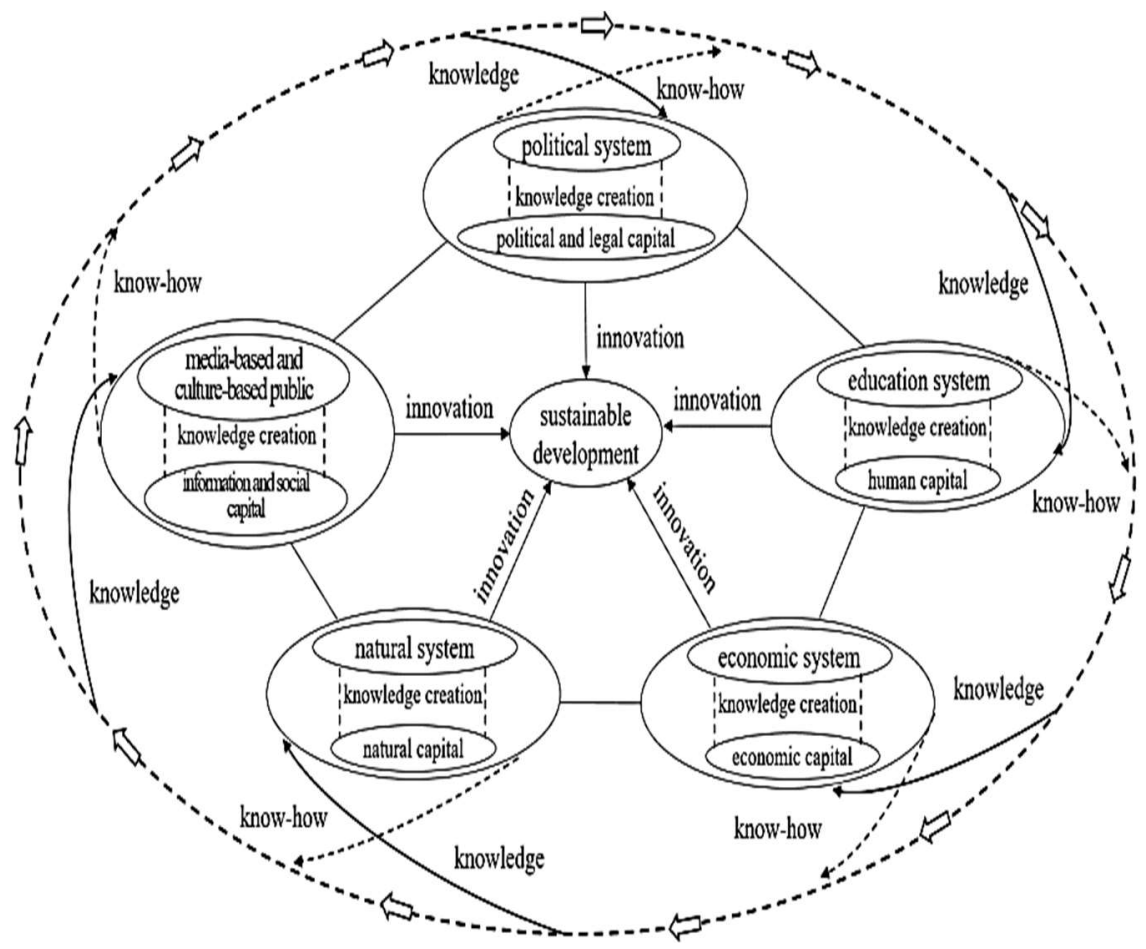

Fig. 3. The Quintuple Helix model. Source: [10].

Thus, in the modern economy, scientific models are gaining popularity, which are based on the need for cooperative interaction of economic entities, the purpose of which is to achieve sustainable development.

\subsection{Evolution of cooperation mechanisms in Russia}

In Russia, over the past 10 years, the trend towards cooperation has become more and more rooted in the program documents of the federal level. Calls for the creation of various forms of collaboration are especially often heard in the scientific and technical sphere as a tool for promoting the socio-economic development of the country.

Clusters can be called one of the first directives attempts by the state to combine business, education and science. The prerequisites for the creation of clusters in Russia were laid back in the era of the planned economy. While in Europe clusters emerged naturally, in the USSR the largest enterprises were forcibly located within the boundaries of territorial-production complexes, science cities or closed administrative-territorial entities [11]. Today in Russia it is these territories that create the core of innovation clusters. 
In Russia, three approaches to the development of cluster policy have been implemented, which are presented in Fig. 4.

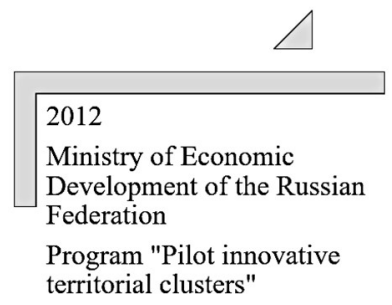

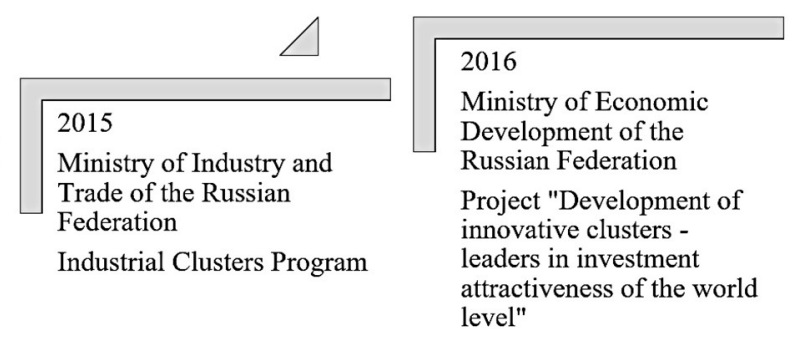

Fig. 4. Stages of the evolution of cluster support in Russia. Source: compiled by the authors.

In 2020, the Ministry of Economic Development of the Russian Federation completed a program to support innovative territorial clusters. The Ministry of Industry and Trade of the Russian Federation still provides support to industrial clusters, but this is mainly expressed in the form of subsidies to cluster members to reimburse part of the costs in the implementation of joint projects for the production of industrial products. In 2020, the Ministry noted the need to move to a new level of cluster development and reorient their development programs [12].

Representatives of the authorities declare the success of the cluster policy in Russia, however, according to the authors, there have been no significant changes in the principles of activity of the main cluster participants during the implementation of the cluster approach [13]. It can be said that the state «lost interest» in cluster policy, having switched to other mechanisms of cooperation, presented below. Poor elaboration of cluster support measures did not lead to the full disclosure of the potential of cluster policy in Russia and the creation of a powerful multiplier effect.

Since 2018, since the signing by Vladimir Putin of the decree «On national goals and strategic objectives of the development of the Russian Federation for the period up to 2024», the development of the economy has been carried out within the framework of 13 national projects [14]. One of them - the National Project «Science» - is aimed, inter alia, at introducing scientific results into the economy and social sphere. For this, a new term was introduced - the World-class Scientific and Educational Center (hereinafter - NOC).

NOC is the most popularized format of scientific and technological cooperation and socio-economic development and in some cases is perceived as a way to access federal funding sources. In NOC, the unification of universities, scientific organizations with organizations operating in the real sector of the economy is carried out without the formation of a legal entity. NOC, in its essence, can be called the successor of the cluster policy in Russia, with an enhanced regional component.

The first five NOC were determined without competitive selection, in accordance with the Address of the President of the Russian Federation to the Federal Assembly of February 20, 2019 [15]. Five more NOC were selected in 2020 as a result of a competitive selection conducted by the Government of the Russian Federation [16].

At the end of 2020, the Government of the Russian Federation approved the program of strategic academic leadership «Priority 2030» (hereinafter - «Priority 2030») [17]. The program is a continuation of the completed Project 5-100 and is aimed at supporting universities. The basis of Priority 2030 is the formation of consortia, which are temporary voluntary associations of universities with other organizations to coordinate activities and consolidate resources. The purpose of uniting into consortia is the development and implementation of breakthrough research 
and development, new creative and social and humanitarian projects, as well as the introduction of high technologies into the economy and social sphere.

It should also highlight the complex scientific and technical programs and complex scientific and technical projects of the full innovation cycle (hereinafter - KNTP) [18]. KNTP is a tool for implementing the Strategy of the Scientific and Technological Strategy of the Russian Federation. The logic of KNTP covers a range of works, from the implementation of applied scientific research to the creation of technologies, products and services. The work can be carried out with the involvement of public authorities, scientific and educational organizations, development institutions. Consortia is not required, but a prerequisite is the presence of a «customer» - an organization of the real sector of the economy interested in using the scientific, scientific and technical results of the KNTP and participating in it.

In mid-2020, the Minister of Science and Higher Education of the Russian Federation V.N. Falkov announced the planned adjustment of the mechanism for implementing the KNTP, since the program did not demonstrate the expected results, and the KNTP approved in Russia have not yet been launched. Nevertheless, the minister stressed the need for further action of the KSTP program [19].

Thus, the focus on supporting cooperation between science, education and business is strengthening on the national agenda. In these conditions, it is important to find the right topics that will be tangible on the economic plane and contribute to the achievement of public policy goals. In doing so, it is important to understand the central figure of cooperation.

Despite the variety of proposed mechanisms, the actual indicators of scientific and technical cooperation in Russia are at a low level. In 2016, in Russia, in comparison with foreign countries, only $34 \%$ of innovatively active companies interacted with the scientific sector in the innovation sphere (for comparison, in the USA - 57\%, in Germany - 46\%) [20].

According to data for 2018 in Russia, organizations that have carried out technological innovations and participate in joint projects interact to a greater extent as partners with scientific organizations. Collaboration with higher education organizations, consumers and suppliers along the value chain, as well as with organizations located in the same group of companies, is approximately equally carried out. There is practically no cooperation with competitive organizations.

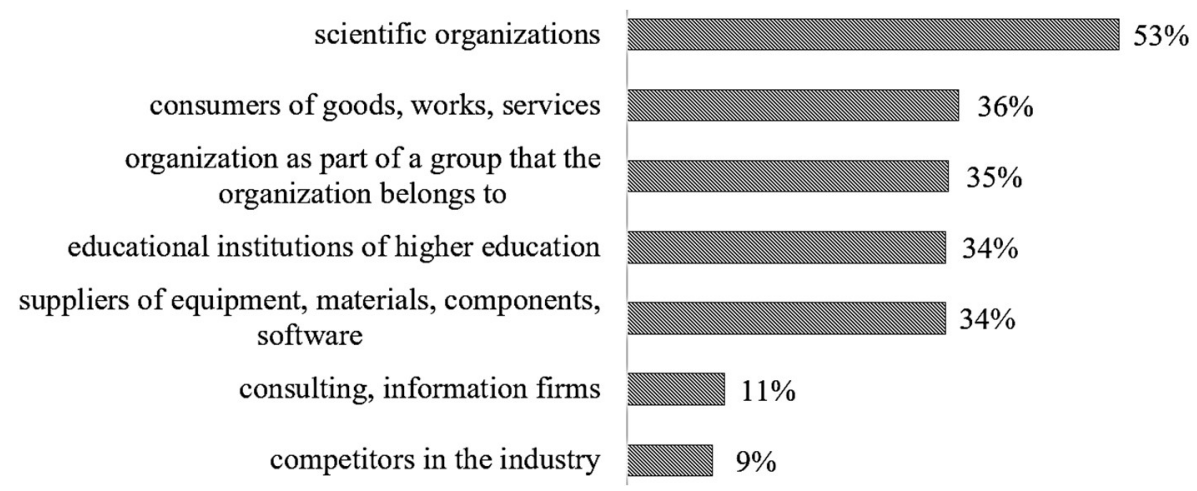

Fig. 5. Distribution of organizations of all types of economic activity in Russia that carried out technological innovations and participated in joint projects, by types of partners for 2018. Source: according to [21].

It can be assumed that the organizations of science and education have significant potential for the development of joint projects with organizations of the real sector of the economy, which, however, is not used sufficiently. 


\section{Materials and methods}

To analyze the potential for the development of cooperative ties between enterprises and educational and scientific organizations, the authors put forward the following provision as a hypothesis:

H1. Scientific and educational organizations have a high potential to involve enterprises in the cooperation process, but they do not use this opportunity.

To test the hypothesis, we used the data obtained as a result of a sample survey of enterprises - participants of the Kama innovative territorial production cluster (hereinafter - cluster), located in the Republic of Tatarstan. The survey participants provided information on the availability of partnerships with organizations of science and education - participants of the cluster in 2017-2021 (for 2021, an assessment of the availability of communication is presented) in two types:

- Research cooperation (includes business contracts, including for the development and implementation of research, $R \& D$, provision of services, etc.).

- Cooperation in the field of education (includes joint programs of additional professional education, targeted training contracts, etc.).

To study the strength of the relationship between the surveyed objects, the methodology of graph theory was applied. This approach makes it possible to assess the degree of cohesion and cooperation within the framework of cluster structures and, according to the authors, is a more objective and correct indicator in comparison with the widespread principle of using the localization coefficient and the Allison-Glazer agglomeration index.

The study assessed the centrality of both individual participants and the cluster as a whole. Centrality characterizes the involvement of a cluster member in various relationships, and, consequently, his position in the cluster. The standardized centrality score is calculated using the formula:

$$
C_{D}\left(n_{i}\right)=\frac{\sum_{j} x_{j i}}{\mathrm{~g}-1}
$$

where $\sum_{j} x_{j i}$ - the sum of the participant's connections, $g$ - number of participants.

In order to compare which of the participants and types of partnerships provides the best centralization, the normalized coefficient of the degree of cluster centralization was calculated:

$$
C_{D}=\frac{\sum_{i=1}^{\mathrm{g}}\left[C_{D}\left(n^{*}\right)-C_{D}\left(n_{i}\right)\right]}{(\mathrm{g}-1)(\mathrm{g}-2)}
$$

where $C_{D}\left(n_{i}\right)$ - the degree of centrality of the participant, $C_{D}\left(n^{*}\right)$ - the maximum degree of centrality of the participant out of all calculated.

The data obtained are presented in table 1.

As you can see, all participants are characterized by low values of centrality, which indicates a low involvement of participants in the cluster. On the other hand, it can be concluded that there is a significant unused potential for cooperation in the cluster. The normalized coefficient of the degree of centralization is higher for organizations of science and education, especially in the direction of research cooperation. This indicates a higher potential for involving organizations of science and education in the cluster, and, consequently, in the process of cooperation.

Further, within the framework of the study, an analysis was made of the relationship between the centrality of enterprises and educational and scientific organizations. For this, a linear correlation coefficient (or Pearson's correlation coefficient) is applied, which is calculated by the formula:

$$
r=\frac{\sum x y-\frac{\sum x \sum y}{n}}{\sqrt{\left(\sum x^{2}-\frac{\left(\sum x\right)^{2}}{n}\right)\left(\sum y^{2}-\frac{\left(\sum y\right)^{2}}{n}\right)}}
$$

where $n-$ is the number of measurements of centrality. 
The calculation results are presented in table 2 .

Table 1. Indicators of the centrality of the participants of the Kama innovative territorial-production cluster.

\begin{tabular}{|c|c|c|c|c|}
\hline \multirow[b]{2}{*}{ g } & \multicolumn{2}{|c|}{ Research cooperation } & \multicolumn{2}{|c|}{ Educational cooperation } \\
\hline & $\begin{array}{c}\mathrm{X} \\
\text { (enterprises) }\end{array}$ & $\begin{array}{c}\text { Y (organizations of } \\
\text { science and education) }\end{array}$ & $\mathrm{X}$ (enterprises) & $\begin{array}{c}\text { Y (organizations of } \\
\text { science and education) }\end{array}$ \\
\hline 1 & 0.33 & 0.27 & 0.07 & 0.43 \\
\hline 2 & 0.13 & 0.60 & 0.21 & 0.50 \\
\hline 3 & 0.07 & 0.07 & 0.29 & 0.00 \\
\hline 4 & 0.20 & 0.13 & 0.29 & 0.14 \\
\hline 5 & 0.07 & 0.00 & 0.07 & 0.00 \\
\hline 6 & 0.00 & 0.07 & 0.07 & 0.00 \\
\hline 7 & 0.00 & 0.07 & 0.00 & 0.00 \\
\hline 8 & 0.00 & 0.13 & 0.00 & 0.07 \\
\hline 9 & 0.13 & 0.07 & 0.00 & 0.00 \\
\hline 10 & 0.00 & 0.00 & 0.00 & 0.00 \\
\hline 11 & 0.00 & 0.07 & 0.00 & 0.00 \\
\hline 12 & 0.27 & 0.00 & 0.14 & 0.00 \\
\hline 13 & 0.00 & 0.07 & 0.00 & 0.14 \\
\hline 14 & 0.07 & 0.00 & 0.00 & 0.00 \\
\hline 15 & 0.20 & 0.00 & 0.21 & 0.07 \\
\hline \multicolumn{5}{|c|}{ Normalized coefficient of the degree of cluster centralization } \\
\hline & 0.05 & 0.09 & 0.04 & 0.07 \\
\hline
\end{tabular}

Source: compiled by the authors.

Table 2. Values of the correlation coefficient for the centrality indicator of enterprises and educational and scientific organizations in the Kama innovative territorial-production cluster.

\begin{tabular}{|l|c|}
\hline $\begin{array}{l}\text { Research cooperation between enterprises and organizations of } \\
\text { science and education }\end{array}$ & Linear correlation coefficient \\
\hline $\begin{array}{l}\text { Cooperation in the field of education between enterprises and } \\
\text { organizations of science and education }\end{array}$ & 0.248 \\
\hline
\end{tabular}

Source: compiled by the authors.

Thus, at this stage, the relationship between enterprises and organizations of education and science in the Kama innovative territorial-production cluster is absent. Initiatives are needed to stimulate cooperation (at least one of the parties, which will entail the involvement of the other party).

Special attention should be paid to the inter-firm relationships of enterprises - members of the cluster. As part of the survey, information was also obtained on the presence of innovative links between the surveyed enterprises (including joint $R \& D$ programs, joint participation in innovation or investment projects, consortia, etc.).

Of the 105 possible pairs of innovation links between enterprises, only 2 pairs were recorded. This indicates an extremely low level of inter-firm cooperation. Revealing the causes is a topic for a separate scientific study, but the authors suggest that one of them may be in the industry specialization of the cluster (which includes petrochemical and automotive enterprises). Russian companies rarely cooperate with industry competitors, preferring other partners. This can be called one of the main reasons for the lack of success of the cluster policy in Russia.

Taking into account the previously made conclusions, it can be assumed that with the strengthening of the role of educational and scientific organizations in cooperative processes, the involvement of enterprises will also increase (which confirms hypothesis $\mathrm{H} 1$ ). 


\section{Results and discussion}

Let us make an assumption that the undisclosed potentials of cooperation between business and educational and scientific organizations are associated with the absence of a unifying theme that could serve as a field of circular economics. For example, for all organizations in the real sector of the economy, technologies and solutions are relevant to reduce waste generation and re-involve them in the production process, increase energy efficiency, and reduce emissions of pollutants into the atmosphere and water bodies.

It has been proven that in European countries, the development of the waste recycling process is directly dependent on the human capital development index and investment in R\&D [22]. Of particular interest is the relationship with the human capital development index, where, according to the authors, universities can play a leading role.

Indeed, for the successful transformation of a linear economy into a circular economy, it is necessary to adjust professional education programs in order to ensure compliance with the competencies of a circular economy. At the initial stage of the transition, it is important to ensure accelerated retraining of personnel employed in traditional sectors of the economy, to form an idea of the necessary transformations in the real sector and to train specialists in new business models. In this way, universities can become guides in the training of personnel for the circular economy.

This, in turn, requires the accelerated formation of educational programs in new areas. A study by the Ellen MacArthur Foundation showed that in 2018 there were 138 higher education institutions in the world offering higher education training in the circular economy [23]. Of these, 61 universities mentioned circular economics in their course titles, while others listed related subject areas in their titles. None of the Russian universities are represented in the study.

Enterprises in Russia have almost no need to interact with education and science, showing independence in many aspects (their own closed-type R\&D centers, corporate universities). Many enterprises do not understand the value of training specialists, searching for employees on the principle of «here and now». At the same time, in most foreign universities, key industrial partners of universities have the predominant right to recruit the best graduates.

It can be concluded that in the context of the transition to the principles of a circular economy, the speed of response of universities in the direction of personnel training will be of critical importance. This will attract enterprises to cooperation and stimulate changes in the real sector of the economy.

\section{Conclusion}

Summing up the results of this study, we can conclude that the organizations of science and education have a high potential for the formation of cooperation mechanisms and the involvement of enterprises in it. Taking into account the special interest in the topic of the circular economy at the international and Russian level, the issue of education and training in accordance with new trends in the economy becomes especially relevant in the process of cooperation.

Taking into account the federal programs in force in Russia, focused on cooperation of scientific and educational organizations with enterprises, it is most expedient to carry out work in this direction through the formation of consortia within the framework of the federal programs «Priority-2030» and KNTP. The initiative to form such consortia in the direction of the circular economy should come from universities. 


\section{References}

1. Towards the circular economy: Economic and business rationale for an accelerated transition, Ellen MacArthur Foundation. Available at: https://www.ellenmacarthurfoundation.org/ assets/downloads/publications/Ellen-MacArthur-Foundation-Towards-the-CircularEconomy-vol.1.pdf (2013).

2. The Ministry of Industry and Trade plans to change the support system for manufacturing and industrial parks. Available at: https://rg.ru/2020/08/09/minpromtorg-izmenitsistemu-podderzhki-promyshlennyh-i-industrialnyh-parkov.html.

3. A. Romanova, E. Ilyina, A. Rakhmatullin. Formation and transformation of capital in the market of information services in the regional economy, Bulletin of Economics, Law and Sociology 1, 45-50 (2015).

4. A. Romanova. Possibilities of internationalization in the integration process of the sphere of educational services, Creative economy 11 4, 419-430 (2017). DOI: 10.18334/ce.11.4.37733.

5. A. Romanova. Designing of educational services in the sphere of housing and communal services, Creative economy 12 3, 329-340 (2018). DOI: 10.18334/ce.12.3.38907.

6. Schools of Thought. Several authors have contributed to refining and developing the circular economy concept. Available at: https://www.ellenmacarthurfoundation.org/ circular-economy/concept/schools-of-thought.

7. M. Braungart, W. McDonough. Cradle to Cradle: Remaking the Way We Make Things, North Point Press, (2002).

8. K. Raworth. Doughnut Economics: Seven Ways to Think Like a $21^{\text {st }}$ Century Economist, Chelsea Green Publishing, (2017).

9. Amsterdam to embrace 'doughnut' model to mend post-coronavirus economy. Available at: https://www.theguardian.com/world/2020/apr/08/amsterdam-doughnut-model-mendpost-coronavirus-economy?CMP=share_btn_fb\&fbclid=IwAR3VMhrBSKfWH8SkjJM DiTjaevniC-1306vryPknhwl-zFCyhMiVUZ2YM9U (2020).

10. E.G. Carayannis, T.D. Barth, D.F. Campbell. The Quintuple Helix innovation model: global warming as a challenge and driver for innovation, J Innov Entrep 12 , (2012). DOI: $10.1186 / 2192-5372-1-2$.

11. L. Graham. Can Russia Compete? A history of innovation in tsarist, soviet and modern Russia, Mann, Ivanov and Ferber, (2014).

12. Vladimir Putin: The problem of climate change requires real action. Available at: https://rg.ru/2020/10/22/putin-problema-izmeneniia-klimata-trebuet-realnyh-dejstvij.html.

13. A. Bagaveeva, D. Sultanova. Methodological approaches to the analysis of cooperative ties in clusters, Economics and Entrepreneurship 12, 397-400 (2020). DOI: 10.34925/EIP.2021.125.12.077.

14. Decree of the President of the Russian Federation of 07.05.2018 № 204 «On national goals and strategic objectives of the development of the Russian Federation for the period up to 2024» (2018).

15. Decree of the Government of the Russian Federation of 30.04.2019 № 537 «On measures of state support for world-class scientific and educational centers based on the integration of educational institutions of higher education and scientific organizations and their cooperation with organizations operating in the real sector of the economy» (2019).

16. Order of the Government of the Russian Federation of 03.12.2020 № 3182-p «On approval of the list of winners of the competitive selection of 2020 for the subsequent provision of state support for world-class research and educational centers based on the integration of educational institutions of higher education and scientific organizations and their cooperation with organizations operating in real economic sector» (2020).

17. Order of the Government of the Russian Federation dated December 31.12.2020 № 3697- 


$$
\mathrm{p}(2020)
$$

18. Decree of the Government of the Russian Federation of 19.02.2019 № 162 «On Approval of the Rules for the Development, Approval, Implementation, Adjustment and Completion of Complex Scientific and Technical Programs of the Complete Innovation Cycle and Complex Scientific and Technical Projects of the Complete Innovation Cycle in order to ensure the implementation of the priorities of scientific and technological development of the Russian Federation» (2019).

19. The Ministry of Education and Science plans to revise the mechanism of complex scientific and technical programs. Available at: https://nauka.tass.ru/nauka/8962385.

20. E. Kuznetsova. Scientific and technological cooperation in Russia: current state, problems and instruments of state support, Spatial development issues 1 (46), 1-12 (2019). DOI: 10.15838/tdi.2019.1.46.4.

21. Indicators of innovative activity: statistical compendium, National Research University «Higher School of Economics», (2020). DOI: 10.17323/978-5-7598-2185-4.

22. A. Khaertdinova, D. Sultanova, D. Iskhakova, A. Karimov. Recycling of Polymers - An Opportunity or a Threat to the Economy?, E3S Web of Conferences 161, 01058 (2020). DOI: $10.1051 / \mathrm{e} 3$ sconf $/ 202016101058$.

23. A global snapshot of circular economy learning offerings in higher education, Ellen MacArthur Foundation. Available at: https://www.ellenmacarthurfoundation.org/assets/ downloads/Global-Snapshot-19.10.18-1.pdf(2018). 